УДК 004.932.72’1

\title{
МЕТОД СЕГМЕНТАЦИИ ИЗОБРАЖЕНИЙ ПО ДИНАМИЧЕСКИМ СПЕКТРАЛЬНЫМ ХАРАКТЕРИСТИКАМ
}

\author{
БОРОДИН А. А. \\ ЧП Мир Инженерньх Решений, Украина, \\ Одесса, 65005, ул. Мельнииякая, 26/2
}

\begin{abstract}
Аннотация. В рассмотренном методе использованы основы биометрии и биорадиолокации для решения задачи сегментации изображений. Используя динамические спектральные характеристики, полученные с помощью вейвлет-спектров, извлечен биометрический признак в виде сигнала изменения яркости пикселей на участке кожи лица, обусловленный сердцебиением. Предлагается использовать квазисогласованные вейвлет-фильтры для эффективного выделения сигнала пульса человека и показана возможность измерения его частоты практически в реальном масштабе времени. Полученные результаты могут быть использованы во многих медицинских приложениях, системах безопасности, идентификации объектов и т. д.

Ключевые слова: обработка изображений в реальном масштабе времени; сегментация изображений; биометрические признаки; динамические спектральные характеристики; вейвлет-преобразование; квазисогласованная вейвлет-фильтрация; измерение пульса
\end{abstract}

Развитие технологий компьютерного зрения на сегодняшний день носит лавинообразный характер. Большой коммерческий успех автоматизированных систем распознавания лиц, жестов, пешеходов и пр. предопределил высокую актуальность разработки новых алгоритмов распознавания образов для систем компьютерного зрения.

Специфической особенностью всех систем распознавания являются повышенные требования к производительности аппаратной части, особенно, когда повышаются требования к точности распознавания и растет обучающая выборка [1]. Любой алгоритм распознавания имеет ограниченное быстродействие и определенную вероятность ошибочного решения [2, 3].

В рамках задач распознавания лиц или жестов по двумерным изображениям, которые включают предварительную подготовку изо- бражения, выделение области интереса, сегментацию по признакам и принятие решения о принадлежности к определенному классу изображений, всегда существуют ограничения в применении полученных решений. Так, в системах распознавания лиц по цветовым признакам кожи, для сегментации участков изображений принадлежащих лицу человека используются признаки кожи в цветовом пространстве HSV и цвето-разностная фильтрация. Этот цветовой базис дает инвариантность к освещению объекта. Однако при работе с изображениями людей разной расовой принадлежности алгоритм сегментации существенно усложняется и уменьшается быстродействие системы в целом. При этом, в случае совпадения цвета фона на изображении с цветом кожи, система дает полный сбой.

В $[4,5]$ предложен принципиально новый подход к решению задач распознавания лиц 